\title{
Inventory "Family Organization and Negative Beliefs" in Maternal Depression: Development and Psychometrics Indicators
}

\author{
Fernanda Aguiar Pizeta ${ }^{1}$ (D) https://orcid.org/0000-0002-9864-1054 \\ Ana Paula Casagrande Silva-Rodrigues ${ }^{2}$ (D) https://orcid.org/0000-0001-9672-5118 \\ Sonia Regina Loureiro ${ }^{2}$ (D) https://orcid.org/0000-0001-9423-2897 \\ Sonia Regina Pasian² (D) https://orcid.org/0000-0002-2811-6625 \\ Anne Marie Fontaine ${ }^{3}$ (D) https://orcid.org/0000-0001-9232-8692
}

\begin{abstract}
This study aimed to describe the development and the empirical evidence of reliability and validity of an instrument that proposes to assess, in the context of maternal depression, family organization resources and cumulative risks in families with school-age children. The items were constructed based on protection processes and developmental outcomes. The Inventory was conducted during a semi-structured interview with a convenience sample: 100 mothers of school-age children, 50 of them diagnosed with recurrent depression and 50 without psychiatric disorders. Agreement analysis between the coding of interviews by independent evaluators indicated values higher than $85 \%$. Based on the exploratory factor analysis, the final composition of the instrument was 31 items, distributed in the dimensions Family Organization and Negative Beliefs, with Cronbach's alpha value of, respectively, 0.72 and 0.87 . Statistically significant differences between the groups with and without depression sustained the discriminant validity of the instrument, enabling its use as a guiding resource for interventions.
\end{abstract}

Keywords: depression, protective factors, risk factors, risk assessment, psychometrics

\section{Inventário “Organização Familiar e Crenças Negativas” na Depressão Materna: Desenvolvimento e Indicadores Psicométricos}

\begin{abstract}
Resumo: O objetivo deste estudo foi descrever o desenvolvimento e evidências empíricas de precisão e validade de instrumento que se propõe a avaliar, no contexto da depressão materna, recursos de organização familiar e riscos cumulativos em famílias com escolares. Os itens foram construídos com base em processos de proteção e riscos desenvolvimentais. O inventário foi administrado no decorrer de entrevista semiestruturada com amostra de conveniência: 100 mães de escolares, sendo 50 delas com diagnóstico de depressão recorrente e 50 sem transtornos psiquiátricos. A análise de concordância entre codificação das respostas por examinadores independentes apontou valores superiores a 85\%. A partir da análise fatorial exploratória, a composição final do instrumento ficou com 31 itens, distribuídos nas dimensões Organização Familiar e Crenças Negativas, com alpha de Cronbach, respectivamente, de .72 e .87. Diferenças estatisticamente significativas entre os grupos com e sem depressão, sustentaram a validade discriminante do instrumento, possibilitando o seu uso como recurso norteador de intervenções.
\end{abstract}

Palavras-chave: depressão, fatores de proteção, fatores de risco, medição de risco, psicometria

\section{Inventario "Organización Familiar y Creencias Negativas” en la Depresión Materna: Desarrollo e Indicadores Psicométricos}

\begin{abstract}
Resumen: El presente estudio tuvo como objetivo describir el desarrollo y las evidencias empíricas de precisión y validez de un instrumento que propone evaluar, en el contexto de la depresión materna, los recursos de organización familiar y los riesgos acumulativos en familias con escolares. Los ítems se construyeron a partir de procesos de protección y riesgos de desarrollo. Se aplicó el inventario durante una entrevista semiestructurada con una muestra de conveniencia: 100 madres de escolares, 50 de ellas diagnosticadas con depresión recurrente y 50 sin ningún trastorno psiquiátrico. El análisis de concordancia entre la codificación de respuestas por examinadores independientes reveló valores superiores al 85\%. Del análisis factorial exploratorio, la composición final del instrumento resultó en 31 ítems, distribuidos en las dimensiones Organización Familiar y Creencias Negativas, con alfa de Cronbach de 72 y de 87, respectivamente. Las diferencias estadísticamente significativas entre los grupos con y sin depresión respaldaron la validez discriminante del instrumento, permitiendo su uso como recurso guía en las intervenciones.
\end{abstract}

Palabras clave: depresión, factores protectores, factores de riesgo, medición de riesgo, psicometría

\footnotetext{
${ }^{1}$ Universidade Paulista, Ribeirão Preto-SP, Brazil

${ }^{2}$ Universidade de São Paulo, Ribeirão Preto-SP, Brazil

${ }^{3}$ Universidade do Porto, Porto, Portugal
}

Support: National Council for Scientific and Technological Development (CNPq) - Grant - 3073 94/2014-0

Correspondence address: Fernanda Aguiar Pizeta. Universidade Paulista Psicologia, Rua Cajueiro 359, Ribeirão Preto-SP, Brazil. CEP 14.040-310. E-mail: fepizeta@gmail.com
Within developmental psychopathology, the success or failure in dealing with typical developmental tasks involves multiple conditions that favor competence and/or dysfunction throughout one's life cycle (Toth \& Cicchetti, 2010). In this interplay, the relevance of protection variables for developmental outcomes is emphasized. These variables promote positive and adaptive responses to risky life events (Juliano \& Yunes, 2014), which are identified as conditions 
or events that increase the probability of physical, social, or emotional problems (Papalia, Feldman, \& Martorell, 2011).

Among the risk conditions for childhood development, the negative impact of maternal depression on children is widely recognized (Goodman et al., 2011). Regarding maternal depression, epidemiological data indicate the presence of significant psychosocial impairments in the family setting of person suffering from the affliction, considering the clinical peculiarities of the depressive disorder and the probability of reoccurring episodes (American Psychiatric Association [APA], 2013), as well as the higher occurrence in women and prevalence of $6 \%$ to $7 \%$ in the general population (World Health Organization [WHO], 2017). The focus of this study is to acknowledge the association of maternal depression with difficulties in the exercise of motherhood and the consequent impact on the school-age children developmental outcomes.

Regarding this, maternal depression is a risk condition for child development in a family setting. It has a direct impact on school outcomes and an indirect impact on a child's mental health, as it is associated with other risk or protection variables in the context of family life (Pizeta, Silva, Cartafina, \& Loureiro, 2013). As for the cumulative risks, scientific literature highlights the predominance of sociodemographic conditions that may influence the structure of the family organization, among them: paternal absence in a child's daily life (Goodman et al., 2011) and few socioeconomic resources (Bouvette-Turcot et al., 2017). Paternal participation in children's activities (Dorsch, Smith, \& McDonough, 2015), presence of effective social support for families (Heberle, Krill, Briggs-Gowan, \& Carter, 2015), and positive educational practices (Elgar, Mills, McGrath, Waschbusch, \& Brownridge, 2007) are highlighted as protective factors that promote a child's adaptive development when living with maternal depression.

Depressive mothers' struggle in providing positive parental care, according to Psychogiou and Parry (2014), requires new studies that seek to broaden the understanding of the mechanisms involved in the association between maternal depression and difficulties in the interactions between mother and child. Among other mechanisms, emphasis should be given to the effect of negative beliefs, which is a variable that impairs depressed mothers of caring for their children. The presence of repetitive negative thoughts is a peculiar characteristic of people with depression and these thoughts are considered to have a negative impact on the quality of interactions between them and their children (Stein et al., 2012).

In this context of cumulative risks, when negative developmental outcomes of children living with maternal depression occur, it is important to broaden the understanding of protection resources that may promote more adaptive responses. As such, to identify, understand, and promote resources for the protection against chronic conditions of risk, Walsh $(2006,2016)$ proposed a mapping of processes that promote positive outcomes in a family setting. These processes are considered from a dynamic and integrative perspective, differing in organizational patterns, communication processes and belief systems (Walsh, 2016).

Family organizational patterns are characterized as internal and external norms that regulate the behavior of family members according to the culture in which they live. Understanding these standards implies assessing the flexibility of these norms, the connection between family members, and social and economic resources available in the family environment. Communication processes, in turn, can be analyzed from clear information exchanges, pleasurable interactions, empathy, and collaborative problem solving. As for the family's belief system, it includes the value attributed to events and interpersonal relationships, contextualizing and signifying adversities (Walsh, 2006). These processes result in the evaluation of relevant elements of the family environment that protect and promote the way it operates. However, when conceptualizing these processes, the author proposes that they should be evaluated through a semi-directed interview (based on a thematic roadmap), even though it may hinder their identification due to the inherent complexity of the subject, which requires that the evaluator have extensive clinical experience. Considering this technical challenge, this study constitutes a proposal for an instrument that systematically evaluates one of these protection resources, based on Walsh's (2016) theoretical perspective, the family organizational patterns, and the operationalization of this proposal of variables that are relevant to development processes. In addition, we suggest the use of a systematic instrument, which also includes concomitant cumulative risk conditions and protection resources. In the scenario of maternal depression, to consider negative maternal beliefs and family organization as variables that are commonly affected by this psychopathology is relevant. However, such variables can also be evaluated in various risk scenarios, with any other women with school-age children.

Regarding family organizational patterns, other studies have highlighted the relevance of a daily routine with defined schedules for the child (Marturano \& Elias, 2016), paternal participation in the child's routine in social commitments and in the demands of daily life (Dorsch et al., 2015), in addition to flexibility in being able to reorganize routines and rules (Walsh, 2016).

By highlighting the family's belief system as a variable of developmental influence, it is observed that negative beliefs are commonly associated with the possibility of failure in a healthy development. Beck (2008), theoretically discussing dysfunctional beliefs in the depression context, identified those as conditions of vulnerability that, in the face of adversity, can promote negative interpretations and beliefs. Negative maternal beliefs are associated with behavioral problems in children and adolescents, which characterizes a vulnerability factor for childhood psychopathology (Gaté et al., 2013). Negative beliefs are also important in understanding the interaction between resources and risks for children's outcomes, considering that cumulative risks has a greater impact on children when compared to their exposure to one single factor, as highlighted by Evans, Li and Whipple (2013).

The complexity inherent in negative beliefs enabled them to be scientifically detailed for several indicators, among which are: (a) signs of rumination, associated with negative thoughts and struggles in problem solving (Watkins \& Moberly, 2009); (b) cognitive bias in the ability to analyze reality when attention directed to negative stimuli is identified (Pearson et al., 2013); and (c) signs of negativity, with disapproval, rejection, or hostility toward oneself (Maughan, Cicchetti, Toth, \& Rogosch, 2007).

On the other hand, empirical studies have sought to identify protection indicators for children with mothers who have 
maternal depression, even though they emphasize the children's personal indicators (Thompson, Mata, Gershon, \& Gotlib, 2017), or the relationship between mothers and children evaluated by a self-reporting questionnaire (Madigan, Brumariu, Villani, Atkinson, \& Lyons-Ruth, 2016). The use of instruments related to protective resources and processes is still limited in the scientific literature. The most commonly used self-report scale is the Family Environment Scale (Guzder, Bond, Rabiau, Zelkowitz, \& Rohar, 2011), which evaluates the family's social environment in three dimensions: relationship, personal growth, and system maintenance, based on dichotomous codes that evaluate the presence of resources and conflicts as true or false. However, instruments that assess protective resources and processes in the context of maternal depression are still lacking.

The mechanisms that influence the impact of cumulative risks associated with maternal depression on the family context, according to Psychogiou and Parry (2014), are poorly understood, although their influence on parenting and the relevance of negative beliefs is clear. Thus, the proposal for an instrument that systematically evaluates both the presence and the quality of protection resources, as well as the negative beliefs, regarding cumulative conditions of development risk, such as the ones that are common in situations of maternal depression, is justified and promising.

In this context, this article aims to describe the development and empirical evidences of reliability and validity of the Family Organization and Negative Beliefs Inventory Beliefs Inventory (The instrument will be available to researchers interested in its use, upon request to the corresponding author). The instrument was based on the theoretical perspective of developmental psychopathology and the interplay design between protection resources and cumulative risks that can influence adaptive developmental outcomes of schoolage children that live with recurrent maternal depression. The Walsh resilience processes (Walsh, 2006, 2016) associated with the family organization was adopted as the resource variables and the negative maternal beliefs as the risk condition that can promote negative outcomes, as these are recurrent in maternal depression. In addition, empirical evidence of its reliability and validity will be presented. The development of this instrument, which proposes to systematically evaluate protection resources (Part 1 - Family Organization) in relation to relevant chronic daily life risks, including recurrent maternal depression, as well as negative maternal beliefs (Part 2 Negative Beliefs) will be described.

\section{Methods}

\section{Procedures for the Development of the Instrument}

Initially, a semi-structured interview was developed (Pizeta, 2014), guided by the processes that promote adaptive outcomes related to the chronic and cumulative risk conditions proposed by Walsh (2006), including the impact of maternal depression on family members and their children (Goodman et al., 2011; Psychogiou \& Parry, 2014). This interview was designed to identify cumulative risk and protection indicators that influence the behavioral outcomes of school-age children living with maternal depression. The Inventory items were constructed from the interview questions, with the initial version containing 42 items, in two dimensions, namely: Part 1 - Family organization and Part 2 - Negative beliefs.

The items contemplated by the final version of the Inventory are presented in Tables 1 and 2. For each variable relevant to the context of maternal depression, such as the quality of the children's routines, one question was designed (ex: As for your child, does he or she follow routines? Describe a typical day for your child.) that could be assessed from specific categories (example of categories in a specific item: The child maintains routine throughout the week; The child maintains routine on the weekend; The child's routine is flexible in the face of unforeseen circumstances), which were grouped according to Inventory items (such as Presence of Routine), so that these could be assessed on the interview.

Next, the development of the Inventory was performed, to be completed by the interviewer grounded on the information obtained in the interview. The Inventory was developed based on procedures described by Pasquali (1999) as necessary for the construction of psychological evaluation instruments. The creation of the Inventory also followed the guidelines of the International Test Commission (ITC, 2010) and, in Brazil, it followed the guidelines of the Brazilian Federal Council of Psychology (Conselho Federal de Psicologia, 2018).

The items were tested for their face and content validity for later application and verification of their psychometric properties as part of a systematic instrument that evaluates the relevant constructs (protective resources, evaluated by family organization, and concurrent risk variable accessed by mothers' negative beliefs). The initial items of the Inventory presented adequate content validity indicators and were examined and improved using semantic analysis by independent evaluators, who based them on a pilot study with a woman/mother with recurrent depression.

Based on these technical strategies, the Inventory was composed of two dimensions: Part 1 - Family Organization, composed of 24 items, with categories that represent latent protective resources variables related to family organization; Part 2 - Negative Beliefs, composed of 18 items related to negative maternal beliefs. The definition and operation of items related to family organization and negative maternal beliefs (Pizeta, 2014) considered variables related to their perception of the family's ability to perform essential tasks, including the ability to: organize established rules and routines and reorganize in the face of unforeseen circumstances and adversity, maintain affective bonds despite the presence of adverse conditions, preserve the roles of each member, and perceive the effectiveness of social and economic resources (social and community networks and financial security).

\section{Procedures Application and Testing of Psychometric Quality Validity and Reliability}

After the formulation of the protection resources items (Part 1 - Family Organization) and concurrent risk factors 
(Part 2 - Negative Beliefs), the Inventory with 42 items, was tested with 100 women/mothers that composed a convenience sample, obtained in public general mental health services. The women were between 25 and 45 years of age (36.2 \pm 5.02) and their respective biological children, of both sexes (50 boys and 50 girls), aged between six and twelve years old $(9.9 \pm 1.69)$. The groups were homogeneous regarding socio-demographic variables, thus constituting a numerically sufficient sample able to support the empirical identification of variables relevant to family organization and maternal beliefs, and able to be evaluated systematically (ITC, 2010).

A total of 50 mothers of school-age children comprised the clinical sample, including women diagnosed with recurrent depression (APA, 2013), and who had experienced moderate or severe episodes in the previous two years, however, had not experienced depressive symptoms in the six months prior to the interviews. The non-clinical group consisted of 50 mothers of school-age children, without psychiatric disorders.

This survey was performed in mental health services of a medium-sized city in the State of São Paulo, Brazil, where 7,721 medical records of over four years of treatment were analyzed. The following were identified: 268 mothers diagnosed with recurrent depression with moderate or severe episodes, and who have school-age children. Of those, 61 mothers were not located and 34 refused to participate. A total of 173 mothers were excluded due to the fact that they demonstrated symptoms of depression at the time of collection (92 mothers); they had other psychiatric disorders (27); and their children had sensory or mental disabilities (four cases), these exclusion criteria were adopted to avoid confounding variables that may interfere in the family organization. Mothers without psychiatric disorders identified in the community (the nonclinical group), were also interviewed. For the selection of this community sample, 153 mothers were identified from a list provided by the primary health service but 39 refused to participate and 27 were not located. Among 87 mothers, 34 demonstrate symptoms of depression or other psychiatric disorders and in three cases, the children presented sensory impairment, 37 mothers were, thus, excluded.

The interviews occurred individually and face-to-face, in places that guaranteed the privacy and confidentiality of the mothers and were applied by trained psychologists with clinical experience. During the application of the script the interviewer had a printed copy of the Inventory (initial version) available, which was completed according the categories of codification (supplementary material) from the mothers' answers during the interview. The interviews had an average duration of 60 minutes. The audio of the interviews was recorded and later transcribed verbatim and in full.

The presence (or absence) of available adaptive resources in the family organization and the negative beliefs were coded. Each item included three categories of codification that were computed as either zero or one point, totaling up to three points per item. The higher the score in Part 1 (Family Organization) of the inventory (resources), the better organization indicators the family was considered to have. On the other hand, the higher the scores for negative beliefs, the more frequent the indicators of bias, rumination or maternal negativity. The Inventory provided the sum of scores of the items and consequent sum of total resources and negative beliefs in each part of the instrument.

The evidence of reliability of the instrument was initially measured in terms of agreement among independent evaluators regarding the coding of interviews by the Inventory according to Bardin's proposition (Bardin, 2011). During the interview, one of the researchers coded the speech of the women interviewed from the Inventory. After that, an independent evaluator performed blind coding for $30 \%$ of the cases of mothers with depression and $30 \%$ of the cases of mothers without psychiatric disorders, totaling 30 participants. When divergences between the independent evaluators' codes occurred, a third researcher decided the difference. The evaluators/researchers were psychologists with clinical experience and previous training in analyzing family protection resources and negative beliefs. The coded data was inserted in an Excel spreadsheet, checked by independent researchers.

To evaluate the structure of the instrument, exploratory factor analysis (EFAs) of the results obtained with the Inventory was performed on this set of 100 participants. Considering the limits of the sample size, these analyses were carried out separately for each of the parties of the Inventory. The analysis occurred using the factorization by the main axis method with Varimax rotation, as the main guiding method, as described in Marôco (2014), for both Family Organization (Part 1) and for Negative Beliefs (Part 2 ) of the Inventory. The adequacy of the results distribution regarding the proposed analysis was verified using the KaiserMeyer-Olkin (KMO) index with a value of 0.655 for the variable of Family Organization (Part 1) and 0.816 for the Maternal Beliefs (Part 2), suggesting that the variables were sufficiently correlated and that the data was adequate enough to perform EFA. These findings were confirmed by Bartlett's sphericity test, which demonstrated $p<.001$ for both analyses.

The first common factors taken from the Inventory were those with an eigenvalue greater than 1 . If these initial results highlighted factors with only one or two items, analyses with a smaller number of factors were conducted until finding a suitable factorial solution to explain the results, covering the greater variance of the findings after the exclusion of items, with the exclusion of the items with similar weights in more than one factor, as well as items that presented commonality values of less than 0.10 . Therefore, the choice of the final factor model and item distribution contemplated the exclusively empirical exploration of the data and indicators related to the proximity of factorial loads and commonality for the exclusion of items, with 16 items from the 24 initially proposed for Part 1 and 15 items out of a total of 18 originally proposed for Part 2.

In addition to this analysis, the accuracy of the two parts of the Inventory and its factors were examined by estimating Cronbach's alpha, identifying the internal consistency.

Finally, the Inventory results of the two groups of mothers interviewed (with recurrent depression and with no psychiatric disorders) were also compared in average terms using the 
Pizeta, F. A., Silva-Rodrigues, A. P. C., Loureiro, S. R., Pasian, S. R., \& Fontaine, A. M. (2019). Family Organization and Negative Beliefs Inventory.

Student's t test, which verified additional construct validity of the proposed inventory. The effect of the possible differences was calculated by means of Cohen's d (Marôco, 2014).

All statistical analyses were performed using the IBM SPSS Statistical software (v.24, IBM SPSS, Chicago, IL), and adopted a significance level of $5 \%$ in the statistical analyses performed.

\section{Ethical Considerations}

The study was approved by the local Research Ethics Committee (CAAE 45984315.9.000.5407) and conducted based on the standards established in the Helsinki Declaration. All participants were volunteers and provided informed consent before the start of the evaluation.

\section{Results}

We will present, firstly, data on agreement between judges and indicators of reliability, followed by the factorial analysis of the Inventory (analysis of its internal structure), then the internal consistency of the subscales and their factorial dimensions, and in the end, the other indicators of validity.

\section{Reliability}

The reliability indicators of the Inventory indicated sufficient agreement among the independent evaluators. An agreement of $87.3 \%$ in Part 1 - Family Organization and $85.0 \%$ in Part 2 - Negative Beliefs was identified, values of which were considered positive as technical indexes.

\section{Factorial Analysis}

Part 1: Family Organization - 16 Items. The final model of the Family Organization part of the Inventory, with the saturation of items by factors, is shown in Table 1 . In this part, the items became important constituents of family stability, maternal care and paternal participation.

The initial extraction of factors with eigenvalues greater than 1 of Part 1 -Family Organization was initially composed of nine factors that accounted for $47.6 \%$ of the total variance. Considering the fragility of certain factors, several AFEs with a smaller number of factors were conducted. During these analyses, eight items from the Part 1 - Family Organization were eliminated. The most satisfactory final model with factor saturation is shown in Table 1.

Table 1

Factorial Weights of each Item in the Three Retained Factors Referring to Part 1 - Family Organization, after an Exploratory Factor Analysis and Factor Extraction Using the Main Component Method and Varimax Rotation $(n=100)$

\begin{tabular}{lcc}
\hline Items - Family Organization & Factors & 2 \\
\hline Routine Planning & .738 \\
Maternal resources in the scheduling of time & .609 \\
Perceived sufficient income & .417 \\
Commitments with the family & .416 \\
Defining rules for the child & .399 \\
Maternal resources to understand when their child needs help & .345 \\
Resources to maintain the child's activities in the face of major difficulties & .646 \\
The child's resources to adapt to new situations & .510 \\
Child's habit of asking for help in the face of difficult situations & .466 \\
Child's resources to deal with everyday situations & .414 \\
Person that stays most of the time with the child & .367 \\
Maternal resources to divide time between the demands of her family and work & .310 \\
Paternal involvement in leisure activities with the child & .766 \\
Paternal involvement in the child's daily routines & .726 \\
Paternal involvement in the child and mother's life & .521 \\
Father accompanies the child's progress at school & .469 \\
\hline
\end{tabular}

The adopted model grouped the 16 items into three factors, with a capacity to explain $32.9 \%$ of the total variance. The model grouped the items in such way to facilitate the analysis of the protection processes that promote childhood adaptive development. For the extracted factors, the percentage of the explained variance of each item varied between $14 \%$ and $60 \%$ (communalities).
Factor 1 was saturated by six items and designated as "Family Stability", it included indicators regarding standards for family organization and perception of financial resources. Factor 2, saturated with six items, was named "Child Resources" and included maternal perception of their child's ability to deal with difficult and new situations, and their own willingness to devote time and attention to the child. In turn, Factor 3, saturated 
by four items, was denominated as "Parental Support", with items related to parental involvement as a source of effective support.

Part 2: Negative Beliefs - 15 Items. The initial extraction of factors with eigenvalues greater than 1 of Part 2 - Negative Beliefs was constituted of three factors that explained $38.3 \%$ of the total variance. Considering the fragility of that structure, several AFEs with a smaller number of factors were conducted. During these analyses, eight items from the Part 2 - Negative Beliefs - were eliminated. The most satisfactory final model for Part 2 of the Inventory, which refers to negative maternal beliefs, with the saturation of items by factors, is showed in Table 2. In this part of the instrument, maternal beliefs regarding the dealing with adversities are evaluated: indicators of bias, rumination, and negativity.

Table 2

Factorial Weights of each Item in the Three Retained Factors Referring to Part 2 - Negative Beliefs, after an Exploratory Factor Analysis and Factor Extraction Using the Main Component Method and Varimax Rotation $(n=100)$

\begin{tabular}{lc}
\hline Items - Negative Beliefs about Bias, Rumination and Negativity & \multicolumn{1}{c}{ Factors } \\
\cline { 2 - 2 } Perception about possible different reactions from what the mother routinely does when difficult situations reoccur & .1 \\
Perception about the possibility of asking for help in dealing with demands related to the child & .678 \\
Perception about what the child needs in everyday life & .663 \\
Perceptions about expectations of the mother when faced with new or difficult situations & .660 \\
Perception about care given to the child & .628 \\
Perception of mother's reactions when difficult problems/situations reoccur & .601 \\
Perception of the child's differences in relation to children of the same age & .533 \\
Perception about the mother's reactions when the child disobey orders & .507 \\
Perception about the possibility of changes in the child's routine when the mother faces (serious or recurrent) difficult situations & .470 \\
Perception as to the sufficiency of the family's financial income & .362 \\
Perception of religious belief of the family & .355 \\
Perception about the mother's reactions when she experiences situations that upset her \\
Perception of facilitating beliefs \\
Perception about the mother's reactions when people think differently from her \\
Perception about which situations upset the mother
\end{tabular}

According to the criteria previously adopted, the final model of the Part 2 - Negative Beliefs of the Inventory was composed of two factors and 15 items, which explained $36.5 \%$ of the total variance. For the extracted factors, the percentage of the explained variance of each item varied between $16 \%$ and $70 \%$ (communalities).

Factor 1 was saturated by 11 items and designated as "Maternal Competence Beliefs", and the beliefs were grouped regarding empathy toward the child and the organization of the family routine, and included the search for external support. Factor 2, which is composed of four items, was named as "Hindering and Facilitating Beliefs", and included negative beliefs about one's own ability to express emotions and deal with new and difficult situations.

\section{Internal Consistency}

For Part 1 - Family Organization, the Cronbach's alpha value was 0.72 , and for the three factors in Part 1 the Cronbach's alpha values were $0.65,0.62$ and 0.71 , respectively. While in Part 2 - Negative Beliefs the Cronbach's alpha value was 0.87 , and for the two factors was 0.87 and 0.67 , respectively.

\section{Construct Validity}

Having defined the internal structure of the Inventory, its discriminative capacity for clinical cases (mothers with depression) and non-clinical cases was examined. It anticipated that mothers with recurrent depression, compared to the averages obtained by mothers without psychiatric disorders, had lower scores for protection resources and higher scores for negative maternal beliefs. Statistically significant differences were identified between the clinical and nonclinical groups for both Part 1 - Family Organization $(t=-6.579 ; \mathrm{p} \leq .001 ; 95 \%$ CI $=-9.0969$; -4.8807; $\mathrm{d}=0.55)$ and for Part $2-$ Negative Beliefs $(t=$ 8.504; $\mathrm{p} \leq .001 ; 95 \% \mathrm{CI}=8.4564 ; 10.3872 ; \mathrm{d}=0.65)$.

For both parts of the Inventory, the data of mothers with recurrent depression and without psychiatric disorders was compared. Regarding the indicators of resources in Part $1-$ Family Organization, mothers with recurrent depression had less resources in the factors "Family Stability" ( $t=-4.293$; $p \leq .001 ; 95 \% \mathrm{CI}=3.5192 ; 1.2939 ; \mathrm{d}=0.44)$ and "Child Resources" $(t=7.790 ; p \leq .001 ; 95 \% \mathrm{CI}=5.0972 ; 3.0258$; $\mathrm{d}=0.59$ ), no significant difference between clinical and nonclinical groups for "Parental Support" was observed. For the 
second dimension, Part 2 - Negative Beliefs, it was identified that the clinical group had significant more negative beliefs in "Maternal Competence Beliefs" $(t=6.790 ; p \leq$. 001; $95 \% \mathrm{CI}=4.4520 ; 8.1467 ; \mathrm{d}=0.57)$ and "Hindering and Facilitating Beliefs" $(t=5.895 ; p \leq .001 ; 95 \% \mathrm{CI}=1.6075$; $3.2442 ; \mathrm{d}=0.53)$. These indicators confirmed the previsions and constitute positive evidence of validity of the proposed inventory, and demonstrate a difference between the cases in the variables under examination (factors of family organization and negative maternal beliefs).

\section{Discussion}

The construction of the Inventory was based on items associated with protection resources and processes, as well as negative maternal beliefs, as these variables are relevant to understanding the family scenario of children living with recurrent maternal depression. These indicators may promote the analysis of concurrent variables for the developmental outcome of school-age children, as moderators or mediators of the impact of maternal depression on the children, which could be the object of future studies. Although the Inventory does not contemplate the full range of family background, which are important variables for child development, the identification of cumulative risks (Evans et al., 2013) and family organization patterns (Walsh, 2006, 2016) configures a set of relevant factors for intervention practices in the context of maternal depression.

The psychometric indicators related to reliability and validity of the Inventory (in its two dimensions) were tested by analyzing the agreement among the independent evaluators regarding items coding of the interview, its structure and internal consistency. Additionally, a validity indicator was presented comparing the average score between clinical and non-clinical groups.

Being an instrument that focuses on the interplay between indicators of protection resources and other risks associated with maternal depression, the factor analysis of the Inventory proposed highlighting the items that best explain the dimensions studied. Regarding resources, it was observed the inclusion in the first dimension of items related to: (a) flexibility of routines as a resource of the family organization that facilitates conviviality and development (Marturano \& Elias, 2016; Walsh, 2016); (b) perceived financial stability, which is associated negatively with maternal depression by Bouvette-Turcot et al. (2017); (c) maternal empathy with the demands of family members (Walsh, 2016); in the second dimension, (d) the child's ability to deal with day-to-day demands of the adult in charge, highlighting the interactive role of family members in identifying child protection resources (Heberle et al., 2015); and the third dimension with (e) paternal involvement as an effective support for the family (Dorsch et al., 2015).

Therefore, the conclusion is that in Part 1 (Family Organization) of the Inventory, it was possible to identify the most relevant protection resources signaled by the literature, both from the maternal figure and from other family members. These findings reiterate the integrative and dynamic role of the perspective proposed by Walsh (2016) to understand the processes promoting adaptive developmental outcomes related to chronic and cumulative risk conditions.

In addition to the resources, access to maternal negative beliefs (Part 2 -Negative Beliefs) allowed us to focus on beliefs about: (a) maternal competence in child care, including beliefs about mothers expectations and actions for care; (b) hindering and facilitating beliefs about difficult events, which highlight maternal beliefs that favor dissatisfaction (negative beliefs) or that help them deal with these difficult situations. When analyzing the risk dimension associated with negative maternal beliefs, the final model identified in this study indicated that they represent important variables associated with maternal depression (Stein et al., 2012), and are unfavorable and cumulative conditions (Evans et al., 2013) in this particular context.

The final model of the inventory proposed in this study emphasized the relevance, for the studied dimensions, of protection resources related to stability of routines, financial and personal support, which includes paternal involvement, and risk factors associated with negative self-perception of maternal competence in taking care of the family and in dealing with difficult events. Thus, it was possible to indicate variables, in the context of recurrent maternal depression, which may be influenced by such psychopathology and by the symptomatological peculiarities of providing protective care for school-age children. However, dealing with the inclusion of mothers without psychiatric disorders, who also expressed their perception about family organization resources and their negative beliefs about maternal competence, the findings demonstrated that these factorial dimension models may also be appropriate for the identification of risk and protective factors for mothers with school-aged children who experience other chronic risk conditions.

It was possible to identify satisfactory indicators of reliability for the proposed Inventory, with a high level of agreement among the evaluators that had been trained in data coding. This result indicates that training in the operation of items and their coding as well as developmental psychopathology allowed the independent evaluators to perform similar coding, for both the identification of protection resources and the negative maternal beliefs in the groups evaluated. Furthermore, the lower mean score for resources in the family environment and higher mean score for negative beliefs of the mothers living with recurrent depression, comparatively with mothers without psychopathology, supports the validity of the Inventory in the evaluation of these constructs. This scenario corroborates data in the literature that mainly shows the association between depression and other indicators of vulnerability and risk, including negativity (Stein et al., 2012). This study advances the frontier of knowledge about family environment variables associated with recurrent maternal depression, as well as identifies which protection indicators are important in the organization of these families.

The data obtained by the reliability and validity analyses of this Inventory allow us to conclude that this is a promising instrument for the evaluation of chronic risk conditions, based on the theoretical perspective of developmental 
psychopathology and on the resilience processes proposed by Walsh $(2006,2016)$, to operate variables that are relevant to the coexistence of multiple recurrent risks. However, unlike the mapping process proposed by Walsh (2006, 2016), the processes promoting the adaptation of this inventory included indicators of organizational patterns and beliefs among family members. Thus, in the experience of the evaluated families, these processes were grouped in a different way from the one presented by the author regarding the three processes of resilience.

Thus, the construction of an instrument that includes indicators of risk and protection of the developmental outcomes of children living with recurrent maternal depression, expressed in a systematic review of the literature, the training of professionals for its use and coding, and the identification of satisfactory psychometric indicators, could broaden the strategies used for assessing the context of these families. This is the reason for the proposal of the Inventory of Family Organization and Negative Beliefs formulated in this study.

The conclusion is that the development and evaluation of psychometric indicators of the Inventory permitted the operation of variables that are relevant to the understanding of the dimensions associated with risk and protection factors for children's development in the context of mothers living with recurrent depression. Thus, the easy identification of concomitant risk and protection factors enable the planning of interventions for the management of difficult and chronic life events, to promote the adaptation of children who live in family contexts permeated by development risks, as is the case of recurrent maternal depression. The systematic procedures for analyzing evidence of validity and reliability of the Inventory now proposed are positive points of this study, as well as the identification and comparison of instrument sensitivity findings for clinical and non-clinical samples that were carefully assessed using a diagnostic tool.

As the limit of the work, the sample size, although sufficient for the analyses performed, may be expanded in future studies to guarantee greater representativeness and include mothers living with other cumulative risk conditions in addition to depression. As such, the exploratory analyses carried out may be increased by the search for additional psychometric indicators for the Inventory of Family Organization and Negative Beliefs, in order to verify if the factorial model identified in this study is confirmed in other samples. Based on the dimensions proposed by the inventory, new empirical studies can also be developed to analyze behavioral and mental health indicators of school-age children living with cumulative risks, as well as possible associations with family organization protection resources, that promote adaptive developmental outcomes.

Despite these limitations, it can be concluded that the instrument is reliable and valid and can be conducted with mothers that have clinical manifestations of depression, showing potential for the assessment of the proposed dimensions, i.e. family organization and negative maternal beliefs, in other samples.

\section{References}

American Psychiatric Association. (2013). Diagnostic and statistical manual of mental disorders (5th ed). Washington, DC: Author.

Bardin, L. (2011). Análise de conteúdo [Content analysis] (L. A. Reto \& A. Pinheiro, Trans.). Lisboa, Portugal: Edições 70.

Beck, A. T. (2008). The evolution of the cognitive model of depression and its neurobiological correlates. American Journal of Psychiatry, 165(8), 969-977. doi:10.1176/ appi.ajp.2008.08050721

Bouvette-Turcot, A. A., Unternaehrer, E., Gaudreau, H., Lydon, J. E., Steiner, M., \& Meaney, M. J. (2017). The joint contribution of maternal history of early adversity and adulthood depression to socioeconomic status and potential relevance for offspring development. Journal of Affective Disorders, 207, 26-31. doi:10.1016/j.jad.2016.08.012

Conselho Federal de Psicologia. Resolução No. 9, de 25 de abril de 2018. (2018, 2 de maio). Estabelece diretrizes para a realização de Avaliação Psicológica no exercício profissional da psicóloga e psicólogo, regulamenta o Sistema de Avaliação de Testes Psicológicos - SATEPSI e revoga as Resoluções No. 2/2003, No. 6/2004 e No. 5/2012 e Notas Técnicas No. 1/2017 e 2/2017 [It establishes guidelines for the performance of Psychological Evaluation in the professional practice of psychologists, regulates the System of Evaluation of Psychological Tests - SATEPSI and repeals Resolutions No. 2/2003, No. 6/2004 and No. 5/2012 and Technical Notes No. 1/2017 and 2/2017]. Diário Oficial da União, seção 1. Retrieved from https://site.cfp.org.br/ wp-content/uploads/2018/04/Resolu\%C3\%A7\%C3\%A3oCFP-n\%C2\%BA-09-2018-com-anexo.pdf

Dorsch, T. E., Smith, A. L., \& McDonough, M. H. (2015). Early socialization of parents through organized youth sport. Sport Exercise and Performance Psychology, 4(1), 3-18. doi:10.1037/spy0000021

Elgar, F. J., Mills, R. S. L., McGrath, P. J., Waschbusch, D. A., \& Brownridge, D. A. (2007). Maternal and paternal depressive symptoms and child maladjustment: The mediating role of parental behavior. Journal of Abnormal Child Psychology, 3(6), 943-955. doi:10.1007/s10802-007-9145-0

Evans, G. W., Li, D., \& Whipple, S. S. (2013). Cumulative risk and child development. Psychological Bulletin, 139(6), 1342-1396. doi:10.1037/a0031808

Gaté, M. A., Watkins, E. R., Simmons, J. G., Byrne, M. L., Schwartz, O. S., Whittle, S., . . Allen, N. B. (2013). Maternal parenting behaviors and adolescent depression: The mediating role of rumination. Journal of Clinical Child \& Adolescent Psychology, 42(3), 348-357. doi:10. 1080/15374416.2012.755927 
Pizeta, F. A., Silva-Rodrigues, A. P. C., Loureiro, S. R., Pasian, S. R., \& Fontaine, A. M. (2019). Family Organization and Negative Beliefs Inventory.

Goodman, S. H., Rouse, M. H., Connel, A. M., Broth, M. R., Hall, C. M., \& Heyward, D. (2011). Maternal depression and child psychopathology: A meta-analytic review. Clinical of Child and Family Psychology Review, 14(1), 1-27. doi:10.1007/s10567-010-0080-1

Guzder, J., Bond, S., Rabiau, M., Zelkowitz, P., \& Rohar, S. (2011). The relationship between alliance, attachment and outcome in a child multi-modal treatment population: Pilot study. Journal of the Canadian Academy of Child and Adolescent Psychiatry, 20(3), 196-202. PMCID: PMC3143695. Retrieved from https:/www.ncbi.nlm.nih.gov/pmc/articles/PMC3143695/

Heberle, A. E., Krill, S. C., Briggs-Gowan, M. J., \& Carter, A. S. (2015). Predicting externalizing and internalizing behavior in kindergarten: Examining the buffering role of early social support. Journal of Clinical Child and Adolescent Psychology, 44(4), 640-654. doi:10.1080/15374416.2014.886254

International Test Commission. (2010). International Test Commission guidelines for translating and adapting tests: Version 2010. Retrieved from http://www. psyktestbarn.no/cms/ptb_mm.nsf/lupgraphics/ITC $\% 20$ guidelines.pdf/\$file/ITC\%20guidelines.pdf

Juliano, M. C. C., \& Yunes, M. A. M. (2014). Reflexões sobre rede de apoio social como mecanismo de proteção e promoção de resiliência [Reflections on the social support network as a mechanism for the protection and promotion of resilience]. Ambiente \& Sociedade, 17(3), 135-154. doi:10.1590/S1414-753X2014000300009

Madigan, S., Brumariu, L. E., Villani, V., Atkinson, L., \& Lyons-Ruth, K. (2016). Representational and questionnaire measures of attachment: A meta-analysis of relations to child internalizing and externalizing problems. Psychological Bulletin, 142(4), 367-399. doi:10.1037/bul0000029

Marôco, J. (2014). Análise estatística com o SPSS Statistics [Statistical analysis with SPSS Statistics] (6th ed.). Pêro Pinheiro, Portugal: Reportnumber.

Marturano,E.M.,\&Elias,L.C.S.(2016).Família, dificuldades no aprendizado e problemas de comportamento em escolares [Family, learning disabilities and behavior problems in schoolchildren]. Educar em Revista, (59), 123-139. doi:10.1590/0104-4060.44617

Maughan, A., Cicchetti, D., Toth, S. L., \& Rogosch, F. A. (2007). Early-occurring maternal depression and maternal negativity in predicting young children's emotion regulation and socioemotional difficulties. Journal of Abnormal Child Psychology, 35(5), 685-703. doi:10.1007/s10802-007-9129-0

Papalia, D. E., Feldman, R. D., \& Martorell, G. (2011). Experience human development (12th ed.). New York, NY: McGraw-Hill.
Pasquali, L. (1999). Instrumentos psicológicos: Manual prático de elaboração [Psychological instruments: Practical elaboration manual]. Brasília, DF: LabPAM.

Pearson, R. M., Fernyhough, C., Bentall, R., Evans, J., Heron, J., Joinson, C., . . . Lewis, G. H. (2013). Association between maternal depressogenic cognitive style during pregnancy and offspring cognitive style 18 years later. American Journal of Psychiatry, 170(4), 434441. doi:10.1176/appi.ajp.2012.12050673

Pizeta, F. A. (2014). Maternal depression, stressors and resilience: Predictors to school-age behavior (Doctoral dissertation). Retrieved from http:/www.teses.usp.br/ teses/disponiveis/17/17148/tde-10112014-213910/

Pizeta, F. A., Silva, T. B. F., Cartafina, M. I. B., \& Loureiro, S. R. (2013). Depressão materna e riscos para o comportamento e a saúde mental das crianças: Uma revisão [Maternal depression and risks for children's behavior and mental health: A review]. Estudos de Psicologia (Natal), 18(3), 429-437. doi:10.1590/S1413-294X2013000300003

Psychogiou, L., \& Parry, E. (2014). Why do depressed individuals have difficulties in their parenting role? Psychological Medicine, 44(7), 1345-1347. doi:10.1017/ S0033291713001931

Stein, A., Craske, M. G., Lehtonen, A., Harvey, A., SavageMcGlynn, E., Davies, B., . . . Counsell, N. (2012). Maternal cognitions and mother-infant interaction in postnatal depression and generalized anxiety disorder. Journal Abnormal Psychology, 121(4), 795-809. doi:10.1037/a0026847

Thompson, R. J., Mata, J., Gershon, A., \& Gotlib, I. H. (2017). Adaptive coping mediates the relation between mothers' and daughters' depressive symptoms: A moderated mediation study. Journal of Social and Clinical Psychology, 36(3), 171-195. doi:10.1521/ jscp.2017.36.3.171

Toth, S. L., \& Cicchetti, D. (2010). The historical origins and developmental pathways of the discipline of developmental psychopathology. The Israel Journal of Psychiatry and Related Sciences, 47(2), 95-104. Retrieved from http://doctorsonly.co.il/wp-content/ uploads/2011/12/2010_2_2.pdf

Walsh, F. (2006). Strengthening family resilience (2nd ed.). New York, NY: Guilford.

Walsh, F. (2016). Family resilience: Strengths forged through adversity. In F. Walsh (Ed.), Normal family processes: Growing diversity and complexity (4th ed., pp. 399-427). New York, NY: Guilford.

Watkins, E. R., \& Moberly, N. J. (2009). Concreteness training reduces dysphoria: A pilot proof-of-principle study. Behaviour Research and Therapy, 47(1), 48-53. doi:10.1016/j.brat.2008.10.014 
World Health Organization. (2017). Depression and other common mental disorders: Global health estimates. Geneva, Switzerland: Author. Retrieved from https:// apps.who.int/iris/bitstream/handle/10665/254610/WHOMSD-MER-2017.2-eng.f;jsessionid=A56D1219939E1F 8CC9E5FF920159F0DE? sequence $=1$

Fernanda Aguiar Pizeta is a Professor of Universidade Paulista, Ribeirão Preto-SP, Brazil.

Ana Paula Casagrande Silva-Rodrigues is a $\mathrm{PhD}$ candidate of Universidade de São Paulo, Ribeirão Preto-SP, Brazil.

Sonia Regina Loureiro is a Professor of Universidade de São Paulo, Ribeirão Preto-SP, Brazil.

Sonia Regina Pasian is a Professor of Universidade de São Paulo, Ribeirão Preto-SP, Brazil.

Anne Marie Fontaine is a Professor of Universidade do Porto, Porto, Portugal.

Authors' Contribution:

All authors made substantial contributions to the conception and design of this study, to data analysis and interpretation, and to the manuscript revision and approval of the final version. All the authors assume public responsibility for the manuscript content.

Received: Nov. 07, 2017

1st Revision: May. 17, 2018

2nd Revision: Jun. 29, 2018

Approved: Jul. 11, 2018

How to cite this article:

Pizeta, F. A., Silva-Rodrigues, A. P. C., Loureiro, S. R., Pasian, S. R., \& Fontaine, A. M. (2019). Inventory "Family organization and negative beliefs" in maternal depression: Development and psychometrics indicators. Paidéia (Ribeirão Preto), 29, e2932. doi: http://dx.doi.org/10.1590/1982-4327e2932 